\title{
Patient radiation dose during angiography and embolization for abdominal hemorrhage: the influence of CT angiography, fluoroscopy system, patient and procedural variables
}

\author{
Conor McCaughey ${ }^{1 *}$ D, Gerard M. Healy², Hanin Al Balushi ${ }^{3}$, Patrice Maher ${ }^{2}$, Jackie McCavana ${ }^{4}$, Julie Lucey ${ }^{4}$ and \\ Colin P. Cantwell ${ }^{2,3}$
}

\begin{abstract}
Background: Angiography and embolization (AE) is a lifesaving, high radiation dose procedure for treatment of abdominal arterial hemorrhage (AAH). Interventional radiologists have utilized pre-procedure CT angiography (CTA) and newer fluoroscopic systems in an attempt to reduce radiation dose and procedure time.

Purpose: To study the factors contributing to the radiation dose of $\mathrm{AE}$ for $\mathrm{AAH}$ and to compare to the reference standard.

Materials and methods: This retrospective single-centre observational cohort study identified 154 consecutive AE procedures in 138 patients (median age 65 years; interquartile range 54-77; 103 men) performed with a C-arm fluoroscopic system (Axiom Artis DTA or Axiom Artis Q (Siemens Healthineers)), between January 2010 and December 2017. Parameters analysed included: demographics, fluoroscopy system, bleeding location, body mass index (BMI), preprocedural CT, air kerma-area product (PKA), reference air kerma $\left(\mathrm{K}_{\mathrm{a}, \mathrm{r}}\right)$, fluoroscopy time (FT) and the number of digital subtraction angiography (DSA) runs. Factors affecting dose were assessed using Mann-Whitney U, Kruskal-Wallis one-way ANOVA and linear regression.
\end{abstract}

Results: Patients treated with the new angiographic system (NS) had a median PKA, median $\mathrm{K}_{\mathrm{a}, \mathrm{r}} \mathrm{Q} 3 \mathrm{PKA}$ and Q3 $K_{a, r}$ that were $74 \%(p<0.0005), 66 \%(p<0.0005)$, 55\% and 52\% lower respectively than those treated with the old system (OS). This dose reduction was consistent for each bleeding location (upper Gl, Lower Gl and extraluminal). There was no difference in PKA $(p=0.452), K_{a, r}(p=0.974)$ or FT $(p=0.179)$, between those who did $(n=137)$ or did not $(n=17)$ undergo pre-procedure CTA. Other factors significantly influencing radiation dose were: patient BMI and number of DSA runs. A multivariate model containing these variables accounts for $15.2 \%$ of the variance in $\mathrm{K}_{\mathrm{a}, \mathrm{r}}$ $(p<0.005)$ and $45.9 \%$ of the variance of PKA $(p<0.005)$.

Conclusion: Radiation dose for AE in AAH is significantly reduced by new fluoroscopic technology. Higher patient body mass index is an independent key parameter affecting patient dose. Radiation dose was not influenced by haemorrhage site or performance of pre-procedure CTA.

Keywords: Angiography, Abdominal: embolisation, Humans, Hemorrhage, Radiation dose, Gastrointestinal, Safety

\footnotetext{
* Correspondence: cmccaugh@tcd.ie

'St James Hospital, Dublin, Ireland

Full list of author information is available at the end of the article
}

\section{Springer Open}

(c) The Author(s). 2022 Open Access This article is licensed under a Creative Commons Attribution 4.0 International License, which permits use, sharing, adaptation, distribution and reproduction in any medium or format, as long as you give appropriate credit to the original author(s) and the source, provide a link to the Creative Commons licence, and indicate if changes were made. The images or other third party material in this article are included in the article's Creative Commons licence, unless indicated otherwise in a credit line to the material. If material is not included in the article's Creative Commons licence and your intended use is not permitted by statutory regulation or exceeds the permitted use, you will need to obtain permission directly from the copyright holder. To view a copy of this licence, visit http://creativecommons.org/licenses/by/4.0/. 


\section{Introduction}

Abdominal arterial hemorrhage (AAH) is a common emergency that is associated with significant morbidity and mortality, with the annual incidence of upper gastrointestinal hemorrhage alone estimated between 61 and 78 per 100,000 (Mullady et al. 2020). Angiography and embolization (AE) is a lifesaving procedure commonly performed by interventional radiology to treat AAH. AE has good technical and clinical success (Hur et al. 2014; Loffroy et al. 2010), but it is performed under fluoroscopic guidance involving a high radiation dose (Mean reference air kerma greater than 1Gy) (Miller et al. 2003), which has implications for the patient, both in terms of short-term deterministic effects (e.g. skin burns (Balter et al. 2010)) and potential long term risk of stochastic effects such as malignancy (Beebe et al. 2016; Lin 2010).

In recent decades, patient radiation dose reduction has become a central component of radiology practice, embodied by the principle 'As low as reasonably achievable' (ALARA) (International Atomic Energy Agency (IAEA) 2018). However, interventional radiology had lagged behind diagnostic radiology in terms of publications on this topic (Hansmann et al. 2017). The reference study for interventional radiology radiation dose levels, the RAD-IR study, produced several publications between 2003 and 09 and these focused upon procedures performed in the United States between 1999 and 2002 (Miller et al. 2003; Miller et al. 2009). In the interval since the RAD-IR study, progressive technological development in fluoroscopic systems have occurred including $\mathrm{x}$-ray energy optimisation and detector quantum efficiency improvements to reduce patient dose. There has been an increase in the use of preprocedural diagnostic computed tomography angiography (CTA) to improve detection and localization of the bleeding site and to reduce patient radiation dose. Two more recent studies from Bundy et al, including patients treated at a single institution in the United States between 2014 and 18 and Baumann et al, including patients treated at a single institution in Europe from 2011 to 14, concluded that radiation doses during fluoroscopic embolization procedures have fallen in the interval since RAD-IR, due to advances in technology and radiation protection practices (Bundy et al. 2018). These studies grouped procedures in different ways, for example Bundy reported the doses for all endovascular embolization procedures combined together $(n=188)$ 'regardless of etiology or intent', whereas RAD-IR and Baumann reported dose for gastrointestinal hemorrhage localization and treatment $(n=94$ and 239 respectively), but did not stratify by bleeding site (upper GI vs lower GI) or include extra-luminal sites of abdominal hemorrhage (e.g., within abdominal solid organs, peritoneum, abdominal wall). These distinctions are important when individualising data for informed patient consent and departmental quality assurance.

We aim to study the factors contributing to the radiation dose of $\mathrm{AE}$ for $\mathrm{AAH}$ and compare radiation dose to the reference standard.

\section{Materials and methods}

Institutional review board approval was received for this retrospective study and the requirement for patient consent was waived. All patients who underwent AE for AAH with haemodynamic instability in our University Hospital between January 1st 2010 and the 31st of December 2017 were included. A list of AE procedures was obtained by a search of the radiology information system. This yielded a database of 204 consecutive procedures. Exclusion criteria were: abdominal aortic aneurysm rupture, obstetric and gynaecological or venous hemorrhage. After exclusions, this yielded a database of 154 procedures. See Fig. 1.

\section{Procedure}

Procedures were performed by one of four fellowship trained interventional radiologists (with 15-, 9-, 9- and 5 -years' experience at the commencement of the study) under general anaesthetic or conscious sedation. Angiography was performed via femoral access. If active bleeding was identified on angiography or an abnormal vessel, selective branch embolization was performed using coils, liquid embolic or particles. If no active bleeding or abnormal vessel was seen, then empiric embolization of the arterial territory suspected as the source of hemorrhage was performed with gelfoam slurry at the operator's discretion.

Procedures were performed on ceiling-suspended single plane angiography systems. Those procedures undertaken from the 1st January 2010 to the 31st of December 2013 were performed on Axiom Artis DTA (Siemens Healthineers), designated the old system (OS), while those procedures performed from the 1st of January 2014 to the 31st of December 2017 were performed on Axiom Artis Q (Siemens Healthineers), designated the new system (NS). The same radiation reduction and procedure protocols were used throughout the duration of the study. Standard methods of dose reduction were observed during every procedure; low pulse rate fluoroscopy, collimation, avoiding magnified views, low dose setting, anti-scatter grids and roadmap overlay technique.

The NS had a number of technical developments that aim to reduce radiation dose without affecting image quality: x-ray tube technology can deliver higher peak power, grid pulse technology facilitates shorter pulses of $\mathrm{x}$-ray, a higher tube current with a higher prefilter produces a narrower spectrum of x-rays with less lower 
204 procedures assessed for eligibility

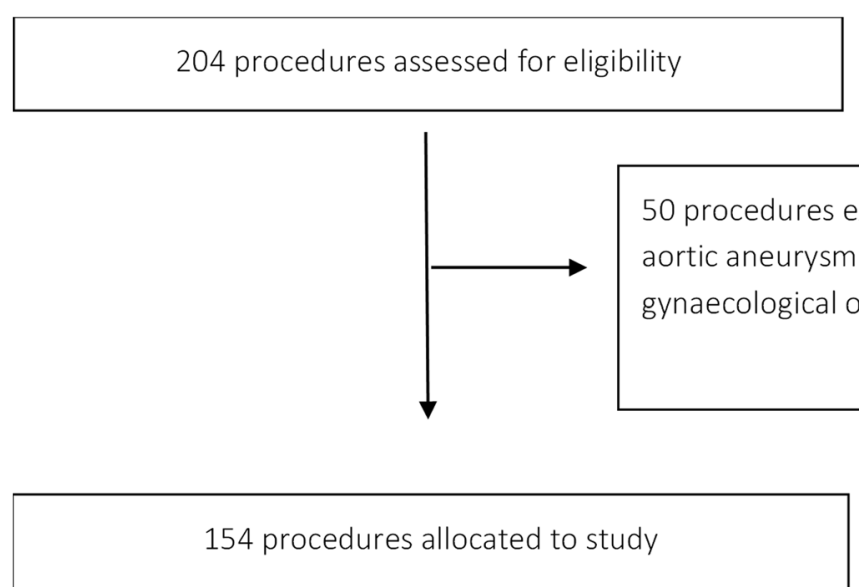

Fig. 1 Flow diagram of patients with hemodynamic instability who underwent conventional angiography (CA) procedures for acute abdominal arterial hemorrhage during the study

energy $\mathrm{x}$-rays and a thicker scintillator leads to superior detector quantum efficiency (DQE). The NS also has post-processing algorithms for image sharpening and edge enhancement.

\section{Pre-procedure CTA}

When deemed to be clinically indicated, pre-procedure abdominal CTA was performed on one of two identical 64-slice CT scanners (Somatom Cardiac CT, Siemens Healthineers, Erlangen, Germany). No oral contrast was administered. All images were reviewed by the operating vascular interventional consultant. Following acquisition of a non-contrast CT abdomen and pelvis range extended from the diaphragm to the symphysis pubis. 150 $\mathrm{ml}$ of low-osmolar iodinated contrast $(340 \mathrm{mg} / \mathrm{ml}$ Iodine or higher concentration) was administered by power injector intravenously at $4 \mathrm{ml} / \mathrm{sec}$. Arterial-phase imaging was triggered using bolus tracking in the abdominal aorta at a density threshold of 125 Hounsfield units. The portal-venous-phase was acquired $25 \mathrm{~s}$ later and/or the delayed phase at 3 minutes after the arterial phase. The utilized CT tube parameter were between 100 and 140 $\mathrm{kV}$ and 180-586 mA. All CT scans were reconstructed and archived with contiguous thin sections of $1 \mathrm{~mm}$ thickness and routine acquisition and archiving of coronal and sagittal reconstructions. CT scans were primarily interpreted by an abdominal imaging fellowship trained attending. Active bleeding was defined as the detection of high-density contrast accumulation in the bowel lumen or an abdominal hematoma between the non-contrast and contrast-enhanced CTA phases. Acute vascular findings included the presence of active bleeding, pseudoaneurysm, truncated/irregular artery or arterio-venous fistula. A hematoma alone on CTA was defined as a negative CTA study.

\section{Data collection}

The patients RISPACS record, clinical and electronic medical records were examined. Patient data was collected: age, sex, height, weight, body mass index (BMI) and BMI category using a computer-based abstraction form developed in a pilot study. For those patients whom height and weight data were incomplete $(n=$ 122), BMI category was estimated from CT waist measurement using a previously described method (International Atomic Energy Agency (IAEA) 2018). We then validated this CT waist measurement method by comparing the results in the 32 patients where complete height and weight data was available.

Clinical data was recorded, including the bleeding location (upper gastrointestinal (GI), lower GI or extraluminal, which included parenchymal, peritoneal or abdominal wall) and if a CTA was performed preprocedure. Procedural and radiation dose data was recorded: fluoroscopy system used, procedure length (time from preparation of the patient's groin until the time of the last image acquired), air kerma-area product (PKA, almost identical to dose area product), reference air kerma $\left(\mathrm{K}_{\mathrm{a}, \mathrm{r}}\right.$, also known as cumulative dose), fluoroscopy time (FT) and the number of digital subtraction angiography (DSA) runs. If a patient had more than one $\mathrm{AE}$ procedure, each procedure was entered as a unique entry in the database.

\section{Statistical analysis}

Baseline categorical variables were compared using a Pearson's Chi square test for independent samples. The distribution of all scale variables was assessed with the Shapiro-Wilk test. Parametrically distributed variables were described using mean and 95\% confidence intervals (CI) and compared using unpaired $t$ tests. Nonparametric variables were described using median and 
interquartile range and were compared using MannWhitney U (two groups), or the Kruskal-Wallis (KW) one-way ANOVA (k groups). In cases where there was a significant difference between groups by ANOVA, posthoc two-way comparisons between groups were performed using Mann-Whitney U test, with Bonferroni correction. For comparison with the RAD-IR study (the reference standard), mean and 95\% CIs were calculated for non-parametric variables where applicable. For ordinal variables, count and percentage were presented and a Mann-Whitney U test was performed. Univariable (UVA) linear regression analysis was performed to identify variables which influenced patient radiation dose. All significant variables from UVA $(p<0.05)$ were entered into multivariate linear regression to create a model for patient radiation dose in the study cohort. All statistical computations were performed in SPSS statistics (version 25; IBM, New York, USA). The alpha value was set at 0.05 .

\section{Results}

138 patients were identified who underwent $154 \mathrm{AE}$ procedures. The baseline characteristics of the entire cohort and the patients treated on the OS and NS are summarised in Table 1. A significantly higher proportion of patients with upper GI bleeding underwent $\mathrm{AE}$ using the new system $(n=29 / 38)$ compared to the OS $(n=9 / 38$, $p=0.046$ ). The groups were well matched in terms of gender and BMI. When the groups were stratified by bleeding location, those with a lower GI bleed were significantly older (median 76 yrs., IQR 60-81) compared

Table 1 Baseline characteristics of patients compared between the old and new fluoroscopy system

\begin{tabular}{llll}
\hline Angiography Suite & OS $(\boldsymbol{N}=\mathbf{6 1})$ & NS $(\boldsymbol{N}=\mathbf{9 3})$ & $\boldsymbol{p}$-value \\
\hline Age $^{\text {a }}$ & $70(53-78)$ & $65(55-75)$ & $0.835^{*}$ \\
Gender & $45(74)$ & $58(62)$ & 0.143 \\
$\quad$ Male & $16(26)$ & $35(38)$ & \\
$\quad$ Female & & & \\
Bleeding Location & $36(59)$ & $49(53)$ & 0.046 \\
$\quad$ Extraluminal & $9(15)$ & $29(31)$ & \\
Upper gastrointestinal & $16(26)$ & $15(16)$ & \\
Lower gastrointestinal & & & \\
BMI Category & $6(10)$ & $4(4)$ & 0.369 \\
$\quad$ Underweight $(<18.5)$ & $13(21)$ & $31(33)$ & \\
Normal (18.5-25) & $22(36)$ & $34(37)$ & \\
Overweight $(>25-<30)$ & $11(18)$ & $14(15)$ & \\
$\quad$ Obese I (30-35) & $9(15)$ & $10(11)$ & \\
Obese II (35-40) & & & \\
\hline
\end{tabular}

Except where indicated, data represent numbers of patients for categories and numbers in parentheses are percentages. a - data represented as median (Q1Q3). OS old system (Axiom Artis DTA), NS new system (Axiom Artis Q) to Upper GI bleed (median 64.5 yrs., IQR 53-71, $p=$ 0.004 ) and extraluminal bleeding (median 65 yrs., IQR 48-76, $p=0.003)$.

Table 2 summarizes the procedure duration, mean FT, number of DSA runs, PKA, $\mathrm{K}_{\mathrm{a}, \mathrm{r}}$ stratified by bleeding location and compared between the machine types (OS, NS and bleeding location with OS and NS). Patients who underwent AE using the NS had a median PKA and $\mathrm{K}_{\mathrm{a}, \mathrm{r}}$ which was significantly lower than those using the OS (median PKA and $\mathrm{K}_{\mathrm{a}, \mathrm{r}}$ were $74 \%$ and $66 \%$ lower respectively; $p<.005)$. The NS also demonstrated significantly lower radiation doses than the OS in patients with extraluminal and lower GI bleeding categories PKA and $K_{\mathrm{a}, \mathrm{r}}$. In patients with upper GI bleeding, PKA was lower with the NS, but there was no significant different in $\mathrm{K}_{\mathrm{a}, \mathrm{r}}$. Boxplots comparing PKA and $\mathrm{K}_{\mathrm{a}, \mathrm{r}}$ by angiographic system and bleeding site are presented in Fig. 2.

A comparison of procedure and radiation exposure metrics, stratified primarily by fluoroscopy system and secondly by bleed location is detailed in Table 3. Procedure time, DSA number, fluoroscopic time and $\mathrm{K}_{\mathrm{a}, \mathrm{r}}$ were not affected by the bleeding location on either fluoroscopy system. There was a significant difference in PKA medians between bleeding locations for the NS by KWANOVA $(p=0.025)$ but post hoc analysis found no significant between group differences (Table 4).

The AE cases preceded by a CTA scan $(n=137)$ did not vary significantly in their procedural parameters; FT $(p=0.179)$, DSA runs $(p=0.929)$, procedure duration $(p=0.094)$, or radiation dose (PKA, $p=0.452$ and $K_{\mathrm{a}, \mathrm{r}}$, $p=0.974)$, in comparison to those who did not have a pre-procedural CTA $(n=17)$.

The univariable and multivariable linear regression analysis of factors influencing radiation dose are detailed in Table 5. In multivariable analysis, the factors significantly influencing the PKA and $\mathrm{K}_{\mathrm{a}, \mathrm{r}}$ were number of the DSA runs, patient BMI and the fluoroscopy system used. Models containing these variables accounted for $45.9 \%$ and $15.2 \%$ of the variance in PKA and $\mathrm{K}_{\mathrm{a}, \mathrm{r}}$ respectively ( $p<0.005$ for both).

The results of the current study compared with those of the RAD-IR are summarised in Table 6. Of note, mean is used as the measure of central tendancy for this table in order to compare with that publication. Of the 94 patients included in part I of the 'RAD-IR' study who underwent fluoroscopic guided embolization for gastrointestinal bleeds, the mean PKA was found to be 34,757 cGy.cm ${ }^{2}$ (95\%CI 2713-129,465 cGy.cm²), and the mean $K_{a, r}$ was found to be 2367 mGy $(95 \%$ CI $2037-2697$ $\mathrm{mGy}$ ). When comparing the mean radiation dose in our cohort with that of the RAD-IR study with the new system, an absolute $66 \%$ reduction was observed (Table 6).

Subsequent analysis of the 94 patients in RAD-IR study led to a size-corrected dose reference levels (DRL) 
Table 2 Comparison of procedure and radiation metrics, stratified by bleed location and angiographic system

\begin{tabular}{|c|c|c|c|c|c|c|}
\hline Location & $\mathrm{N}$ & Duration (mins) & DSA runs & FT (seconds) & PKA (cGy.cm2) & $\mathrm{Ka}, \mathrm{r}$ (mGy) \\
\hline \multicolumn{7}{|c|}{ Extra-luminal } \\
\hline OS & 36 & $55(38-74.5)$ & $8(6-10)$ & $944.5(661.5-1551.5)$ & $23,694(15011-35,681)$ & $1200(500-2000)$ \\
\hline NS & 49 & $65(40-89)$ & $7(5-10)$ & $1212(738-1673)$ & $8618(3984-24,330)$ & 635 (249-1668) \\
\hline$\%$ & & & & & 64 & 47 \\
\hline$p$ & & & & & $<0.005$ & 0.03 \\
\hline \multicolumn{7}{|l|}{ Upper Gl } \\
\hline OS & 9 & $41(30-56)$ & $9(6-10)$ & 1378 (874-2395) & $13,736(10078-30,681)$ & $950(550-1850)$ \\
\hline NS & 29 & $54(40-80)$ & $8(4-12)$ & $885(662-1749)$ & $5511(1545-11,686)$ & $327(114-847)$ \\
\hline$\%$ & & & & & 60 & 70 \\
\hline$p$ & & & & & 0.018 & 0.064 \\
\hline \multicolumn{7}{|l|}{ Lower Gl } \\
\hline OS & 16 & $48(27.5-64.5)$ & $9(6-11)$ & $979.5(622-1370)$ & $28,788(14573-41,471)$ & $1200(500-2450)$ \\
\hline NS & 15 & $56(34-76)$ & $7(4-8)$ & 747 (562-1778) & 2906 (2435-7387) & $344(186-424)$ \\
\hline$\%$ & & & & & 90 & 71 \\
\hline$p^{-}$ & & & & & $<0.005$ & 0.002 \\
\hline \multicolumn{7}{|c|}{ All locations } \\
\hline OS & 61 & $51(35-71)$ & $8(6-10)$ & 1009 (672-1524) & $23,786(14010-36,992)$ & $1150(500-2000)$ \\
\hline NS & 93 & $60(40-86)$ & $7(4-9)$ & 1083 (664-1744) & $6227(2435-16,568)$ & 408 (183-953) \\
\hline$\%$ & & & & & 74 & 66 \\
\hline$p$ & & & & & $<0.005$ & $<0.005$ \\
\hline
\end{tabular}

Unless otherwise stated, values are represented as the median, with the parenthesis containing the interquartile range

FS Fluoroscopy System, OS old system (Axiom Artis DTA), NS new system (Axiom Artis Q), FT - fluoroscopy time, PKA air kerma-area product, $K_{a, r}$ reference air kerma, \% Percentage change between systems

for gastrointestinal hemorrhage AE procedures of PKA of 31,915 cGy.cm ${ }^{2}$ (95\%CI 26,916-36,082 cGy.cm²), and $\mathrm{K}_{\mathrm{a}, \mathrm{r}} 2056$ mGy (95\%CI 1797-2599 mGy). The same analysis suggested a DRL not-corrected for body habitus of PKA 52,000 cGy.cm ${ }^{2}, \mathrm{~K}_{\mathrm{a}, \mathrm{r}} 3800 \mathrm{mGy}$, FT $35 \mathrm{~min}$ and 425 images (Miller et al. 2009). Our data would suggest the following DRLs (PKA, $K_{\mathrm{a}, \mathrm{r}}$ and FT respectively) for patients undergoing $\mathrm{AE}$ for $\mathrm{AAH}$, derived from the upper quartile values for the new system stratified by location: Extraluminal bleeding 24,300 cGy.cm² 1668 mGy, 27.88 min, upper GI bleeding 11,686 cGy.cm², 847 mGy, 29.15 min and lower GI bleeding $7387 \mathrm{cGy}_{\mathrm{cm}}^{2}, 424 \mathrm{mGy}$, $29.63 \mathrm{~min}$. When comparing the DRL in our lower gastrointestinal hemorrhage cohort on the NS with the RAD-IR DRL, our cohort PKA was 53\% less, $K_{a, r} 89 \%$ less and with comparable FT. A graph of the mean
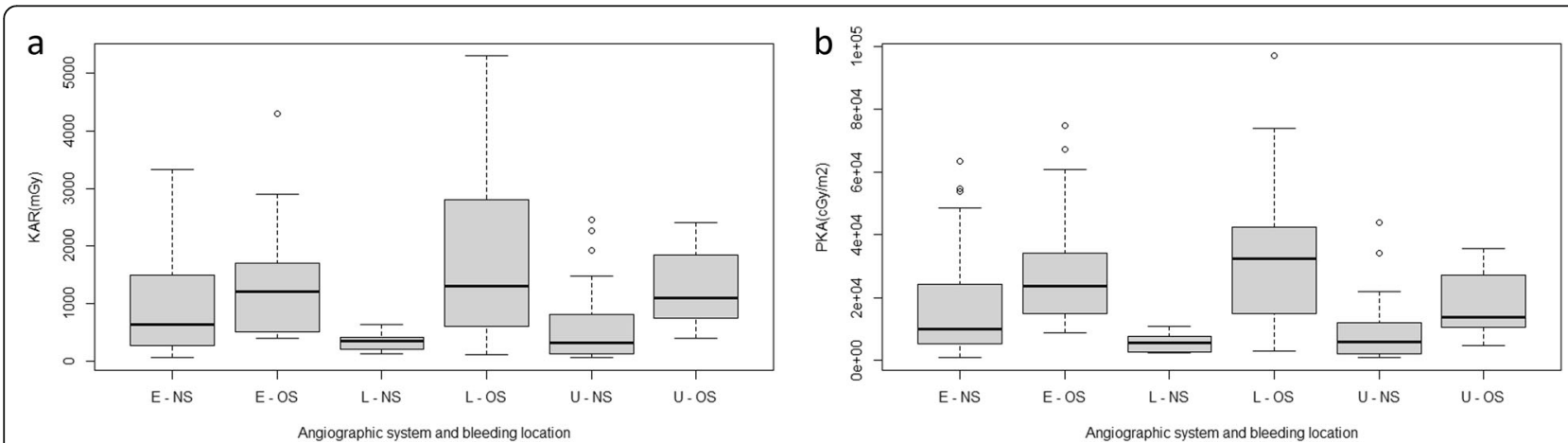

Fig. 2 a Boxplot comparing reference air kerma $\left(K_{a, r}\right)$ between fluoroscopy systems, stratified by location. b Boxplot comparing air kerma-area product (PKA) between fluoroscopy systems, stratified by location. Values displayed as median and interquartile range. Outlying values denoted by circles. E=Extraluminal, L=lower Gl and U=Upper Gl; OS- Old system, NS- New System 
Table 3 Comparison of procedure and radiation exposure metrics, stratified by fluoroscopy system and bleed location

\begin{tabular}{|c|c|c|c|c|c|c|}
\hline Location & $\mathbf{N}$ & Duration (mins) & DSA runs & FT (seconds) & PKA (cGy.cm2) & $\mathrm{K}_{\mathrm{a}, \mathrm{r}}(\mathrm{mGy})$ \\
\hline \multicolumn{7}{|l|}{ OS } \\
\hline Extraluminal & 36 & $55(38-74.5)$ & $8(6-10)$ & $944.5(661.5-1551.5)$ & $23,694(15011-5681)$ & $1200(500-2000)$ \\
\hline Upper Gl & 9 & $41(30-56)$ & $9(6-10)$ & $1378(874-2395)$ & $13,736(10078-0681)$ & $950(550-1850)$ \\
\hline Lower Gl & 16 & $48(27.5-64.5)$ & $9(6-11)$ & $979.5(622-1370)$ & $28,788(14573-41,471)$ & $1200(500-2450)$ \\
\hline Subtotal & 61 & $51(35-71)$ & $8(6-10)$ & 1009 (672-1524) & 23,786 (14010-6992) & $1150(500-2000)$ \\
\hline$p$-value & & 0.367 & 0.768 & 0.534 & 0.349 & 0.794 \\
\hline \multicolumn{7}{|l|}{ NS } \\
\hline Extraluminal & 49 & $65(40-89)$ & $7(5-10)$ & $1212(738-1673)$ & $8618(3984-24,330)$ & 635 (249-1668) \\
\hline Upper Gl & 29 & $54(40-80)$ & $8(4-12)$ & 885 (622-1749) & $5511(1545-11,686)$ & $327(114-847)$ \\
\hline Lower Gl & 15 & $56(34-76)$ & $7(4-8)$ & 747 (562-1778) & 2906 (2435-7387) & $344(186-424)$ \\
\hline Subtotal & 93 & $60(40-86)$ & $7(4-9)$ & $1083(664-1744)$ & $6227(2435-16,568)$ & 408 (183-953) \\
\hline$p$-value & & 0.684 & 0.596 & 0.516 & $0.025^{*}$ & 0.055 \\
\hline
\end{tabular}

OS old system (Axiom Artis DTA), NS new system (Axiom Artis Q), FT fluoroscopy time, PKA air kerma-area product, $K_{a, r}$ reference air kerma. *- There was a significant difference in PKA medians between bleeding locations for the NS by KW-ANOVA $(p=0.025)$ but post hoc analysis found no significant between group differences (Table 4)

results of FT and mean $\mathrm{K}_{\mathrm{a}, \mathrm{r}}$ and PKA compared between RAD-IR and our study (OS, NS) shows reducing dose parameters and relatively stable FT, see Fig. 3.

\section{Discussion}

The results of this study confirm that newer generation interventional radiology fluoroscopy systems, with more advanced technology, have the potential to significantly decrease the radiation being delivered to patients undergoing fluoroscopic guided procedures. The predictors of radiation exposure to the patients in our cohort were the fluoroscopic system used, the number of DSA runs and patient BMI, whereas the use of pre-procedural CTA or the location of bleeding did not impact on radiation dose.

Angiography equipment is the largest determinant of radiation dose for $\mathrm{AE}$ procedures. We have demonstrated a $66 \%$ reduction in $\mathrm{K}_{\mathrm{a}, \mathrm{r}}$ and $74 \%$ reduction in PKA at our centre with the introduction of a new angiographic system. The reference study in this field is RADIR (Miller et al. 2003; Miller et al. 2009) and judging by overlapping confidence intervals (Table 6), our OS demonstrated no significant difference compared to the RAD-IR doses, but the NS demonstrated a significant

Table 4 Adjusted $p$-values for the post hoc analysis of air kerma-area product for bleed locations using the new angiographic system

\begin{tabular}{lll}
\hline & Extraluminal & Upper Gl \\
\hline Upper Gl & $0.072(\mathrm{~W}=764)$ & - \\
Lower Gl & $0.072(\mathrm{~W}=341)$ & $0.899(\mathrm{~W}=153)$
\end{tabular}

Mann Whitney $U$ test with Bonferroni Correction used for post-hoc analysis of difference in air-kerma product between bleeding locations for the new angiographic system. The Mann-Whitney statistic (W-value) is displayed in brackets dose reduction, as measured by both outcome measures (65.8\% reduction in PKA and $67.1 \%$ reduction in $\mathrm{K}_{\mathrm{a}, \mathrm{r}}$, Table 6). There is a clear trend of iterative improvement in radiation doses for this procedure over the past two decades (Fig. 1), however the fluoroscopy (Table 6) and procedure times (Fig. 3) are unchanged, suggesting similar procedure techniques and procedure difficulty across these studies. Our NS was also significantly lower than the recent European cohort of 139 patients who underwent $\mathrm{AE}$ for gastrointestinal bleeding between 2013 and 2014 (mean $\mathrm{K}_{\mathrm{a}, \mathrm{r}} 1342.9$ mGy, 95\% CI 1128.6-1557.2, compared to mean $778 \mathrm{mGy}, 95 \%$ 594-962 from our NS), although they did not report PKA (Baumann et al. 2017). Therefore, the RAD-IR radiation doses and DRLs should no longer be considered the gold standard for this procedure, considering the changes in $\mathrm{x}$-ray technology. This is supported by similar reductions in patient radiation dose in other recent studies of interventional procedures using new fluoroscopic technology, including uterine fibroid embolization (PKA reduction 77\%) (Thomaere et al. 2018), TACE for hepatocellular carcinoma (PKA reduction 66\%) (Schernthaner et al. 2015), bronchial artery embolization (PKA reduction 59\%) (Spink et al. 2017) and cardiac catherization/angioplasty (PKA reduction 67\%) (Buytaert et al. 2018).

CT angiography is sensitive in detecting and localising the source of hemorrhage. Pre-procedural CTA did not impact the patient radiation dose, fluoroscopy time or procedure duration during $\mathrm{AE}$ in this analysis. It has previously been shown that pre-procedure CTA does not influence the fluoroscopy time in lower GI hemorrhage angiography/embolization procedures (Jacovides et al. 2015), although we are not aware of any prior studies looking at the impact on radiation dose. 
Table 5 Univariate and multivariate linear regression modelling of factors influencing radiation dose $(n=154)$

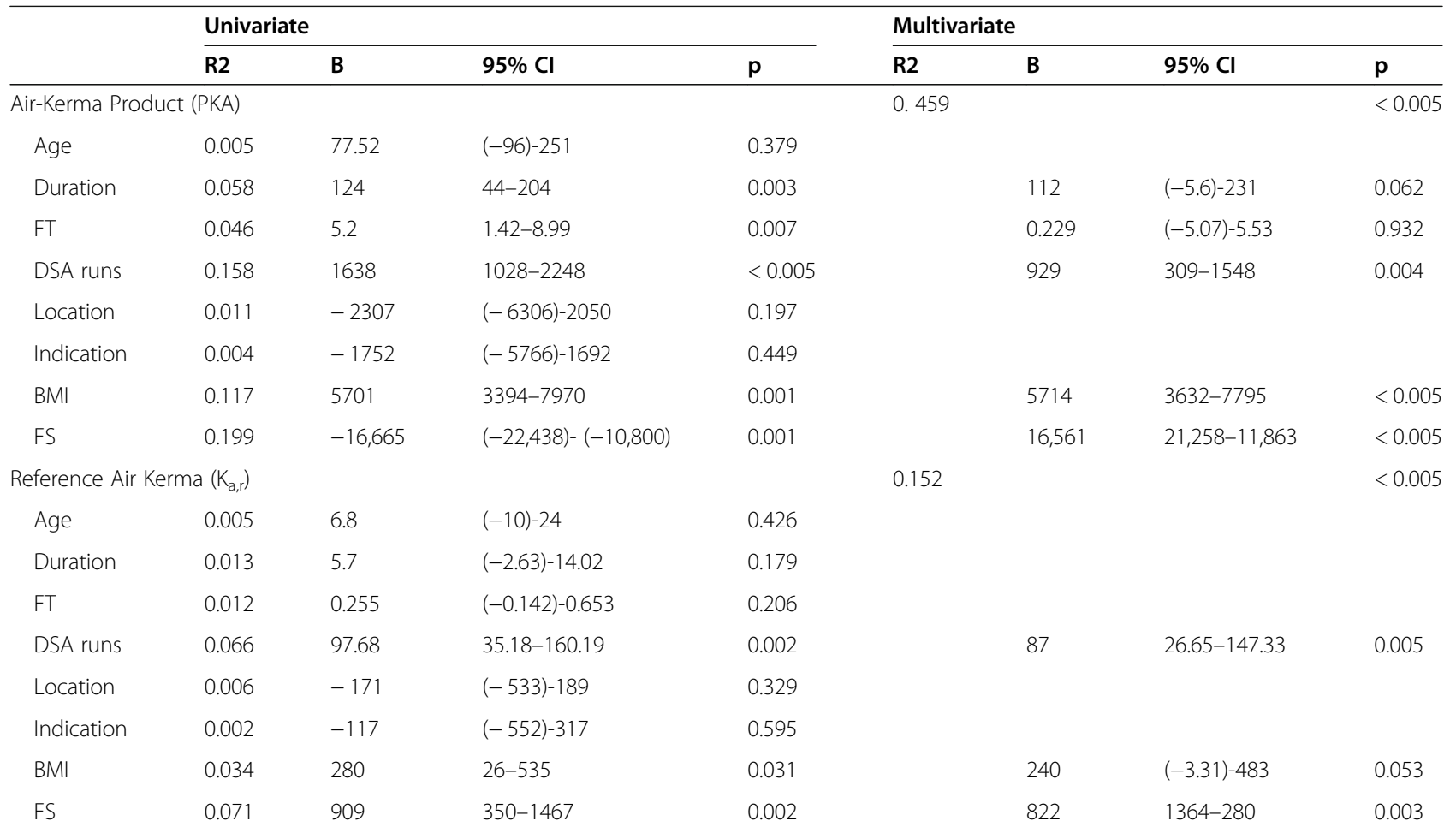

Table 5 displays the results of both the univariate and multivariate regression analysis of the patient and procedural factors influence on patient radiation dose, measured as both PKA (air kerma-area product) and $\mathrm{K}_{\mathrm{a}, \mathrm{r}}$ (reference air kerma). Only those factors that were found to have a significant impact on radiation dose during the univariate analysis were included in the multivariate analysis

FT Fluoroscopy Time, FS Fluoroscopy System

There are other potential benefits of doing preembolization CTA, such as excluding patients who do not have active bleeding (Shukla et al. 2017; Foley et al. 2010), planning arterial access, planning procedural technique (Sommer et al. 2010), identifying the site (Jacovides et al. 2015) and cause of bleeding (for example, underlying malignancy) (Wells et al. 2018) and providing vital information for other services who may be involved in treating the patient (gastroenterology, surgery) (Jacovides et al. 2015). Hence, pre-procedure CTA will remain part of our local treatment algorithm for patients with suspected abdominal arterial haemorrhage.
Tabulating and publishing updated patient radiation doses for $\mathrm{AE}$ is relevant both for informed patient consent and departmental quality assurance. Studies have demonstrated that the majority of patients and physicians are either not aware or underestimate the potential risks associated with radiation in medical imaging (Lam et al. 2015), yet the majority of patients feel that anticipated procedure dose and associated radiation risks should be discussed with them as part of the consent process (Lam et al. 2015; Zener et al. 2018), even in the emergency setting (Takakuwa et al. 2010). Long fluoroscopic guided procedures, such as embolization, fall into

Table 6 Comparison of procedure number, mean fluoroscopy time, air kerma-area product, reference air kerma between the RAD-IR study, old fluoroscopy system and new fluoroscopy system

\begin{tabular}{|c|c|c|c|c|c|c|c|}
\hline & \multirow[t]{2}{*}{$\mathrm{N}$} & \multicolumn{2}{|l|}{ FT (min) } & \multicolumn{2}{|l|}{ PKA (cGy.cm2) } & \multicolumn{2}{|l|}{$\mathrm{K}_{\mathrm{a}, \mathrm{r}}(\mathrm{mGy})$} \\
\hline & & Mean $(95 \% \mathrm{Cl})$ & Range & Mean $(95 \% \mathrm{Cl})$ & Range & Mean $(95 \% \mathrm{Cl})$ & Range \\
\hline RAD-IR & 94 & $25.8(22.2-29.5)$ & $3.5-93.7$ & $34,757(30,599-38,915)$ & $2713-129,465$ & 2367 (2037-2697) & $105-7160$ \\
\hline OS & 61 & $19.6(16.4-22.8)$ & $1.33-61.9$ & $28,540(23,524-33,555)$ & $138.5-96,876$ & $1688(1074-2302)$ & $100-17,100$ \\
\hline \% Reduction compared to RAD-IR & & 24.0 & & 17.9 & & 28.7 & \\
\hline NS & 93 & $20.8(18.1-23.4)$ & $0.6-62.4$ & $11,875(8979-14,770)$ & $261-63,118$ & $778(594-962)$ & $52.8-3323$ \\
\hline \% Reduction compared to RAD-IR & & 19.4 & & 65.8 & & 67.1 & \\
\hline
\end{tabular}

Note: The RAD-IR study used mean and not median values for FT, PKA and $\mathrm{K}_{\mathrm{a}, \mathrm{r}}$. Percentage reduction of PKA and $\mathrm{K}_{\mathrm{a}, \mathrm{r}}$ are calculated relative to the RAD-IR mean dose. $N$ number, OS old system (Axiom Artis DTA), NS new system (Axiom Artis Q), BMI body mass index, $F T$ fluoroscopy time, $P K A$ air kerma-area product, $K_{a, r}$ reference air kerma. $N / A$ not available 


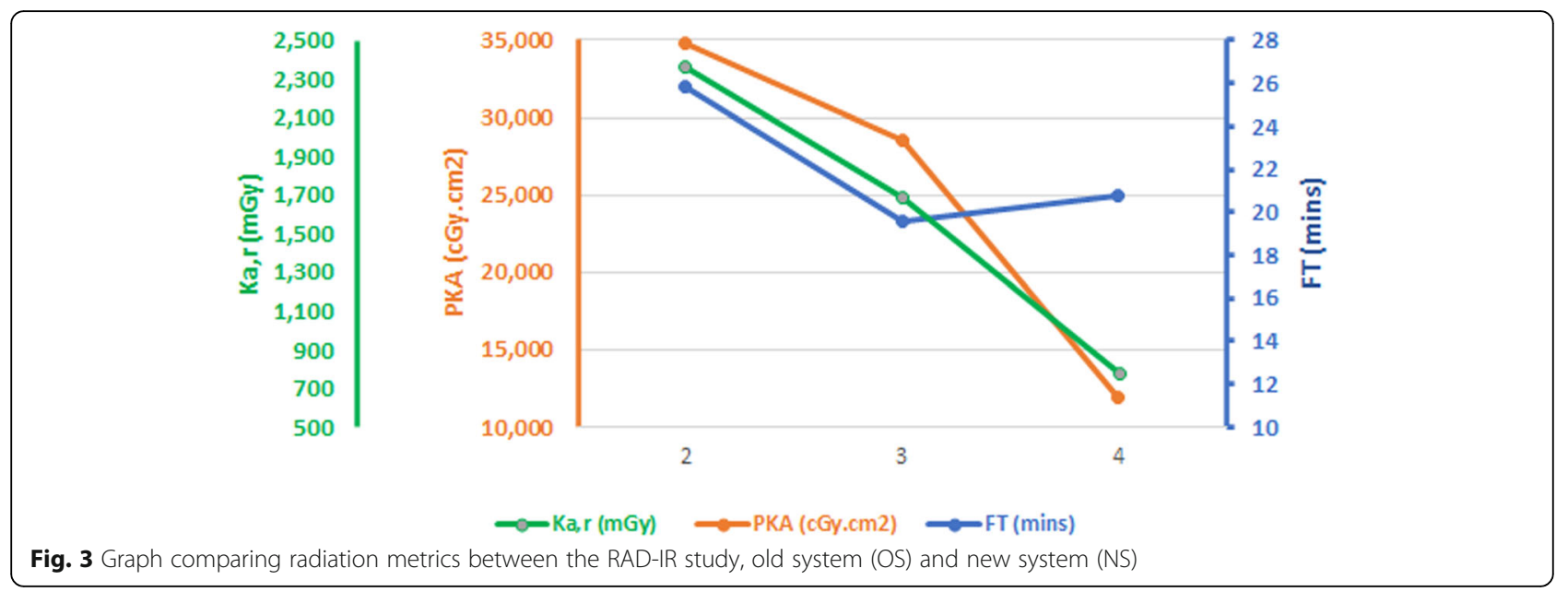

the category of high dose radiology studies (>1 mSv), for which a dedication discussion of radiation is advised during patient informed consent (Semelka et al. 2012). There is a considerable volume of misinformation in the general media about medical radiation, which can cause patient anxiety (Hendee and O'Connor 2012), but there is evidence to show that when a patient has accurate knowledge of the risks involved, along with the indication for the procedure/test, they are unlikely to decline (Zener et al. 2018; Takakuwa et al. 2010). Hence, there is a clear need for further education. Gathering procedure-specific data is essential to inform this process.

Information on the impact of BMI can further help to personalize the risks communicated to the patient, since radiology dose management for obese patients in IR has been highlighted as particularly important in guidelines (Zener et al. 2018). The positive correlation between BMI and radiation dose in fluoroscopy has been demonstrated previously in several studies, including in uterine fibroid (Lacayo et al. 2020), prostate artery (Barral et al. 2021) and visceral embolization (Baumann et al. 2017). In our study, for every increase in BMI category (for example from underweight to normal), a patient's dose increased on average by 5714 cGy.cm2 (95\%CI 36327795), as measured by PKA.

Quality assurance programs and regular audit are essential components of radiation dose optimization for any radiology department and they require accurate, relevant and up-to-date reference standards (dose references levels, DRL) from which to compare local performance (Tsapaki 2020). This is essential in order to identify equipment malfunction, incorrect protocols and/or deviations from normal practice by the users. This data may also be used in business cases for equipment upgrades. Pilot studies have shown that artificial intelligence algorithms could be useful in radiation quality assurance, however accurate training data with detailed labels (i.e., procedures specific radiation doses) are required in order train and validate such algorithms (Neri et al. 2019; Meineke et al. 2019).

This single-site retrospective study presents several limitations. The radiation doses described may not be generally applicable due to the impact of confounding variables including configuration and protocol differences between equipment, patient positioning, local practice patterns and operator experience. Additionally, as both systems were serially assessed, increased operator experience could represent a confounding factor in the decreased radiation exposure observed with the NS. However, the absence of observed significant differences in procedure metrics between both groups would suggest this was not a significant factor. The impact of patient anatomy and pathology was not considered and may affect the complexity of cases. The number and quality of images was neither recorded nor qualitatively assessed. Conclusions regarding the impact of preprocedure $\mathrm{CT}$ on radiation exposure may be limited by the small number of patients who did not undergo preprocedure CT $(n=17)$.

We cannot fully determine the significance of the reduction in radiation dose between RAD-IR and our cohort due to the absence of demographic and other details in the RAD-IR publication.

\section{Conclusion}

Patient radiation dose during angiography and embolization in acute abdominal hemorrhage are significantly influenced by fluoroscopy technology, lower body mass index patients and the number of DSA runs performed. Site of hemorrhage does not affect radiation dose. Performance of a pre-procedure CTA may not impact procedure dose.

\section{Abbreviations}

$\mathrm{AAH}$ : Abdominal arterial hemorrhage; AE: Angiography and embolization; ANOVA: Analysis of variance; BMI: Body mass index; Cl: Confidence interval; 
CTA: Computed Tomography Angiography; DSA: Digital subtraction angiography; DRL: Dose reference level; FT: Fluoroscopy time; $\mathrm{K}_{\mathrm{a}, \mathrm{r}}$ : Reference air kerma; KW - ANOVA: Kruskal-Wallis (KW) one-way ANOVA; NS: New system; OS: Old System; PKA: Air kerma-area product; UVA: Univariable analysis

\section{Acknowledgments}

Not applicable.

\section{Authors' contributions}

CC and GH contributed to study conception and design, $\mathrm{CMCC}$ and $\mathrm{HB}$ performed data collection; $\mathrm{CMCC}, \mathrm{GH}, \mathrm{PH}, \mathrm{JMCC}$, JL and CC contributed to analysis and interpretation of results; $\mathrm{CMCC}, \mathrm{GH}$ and $\mathrm{CC}$ contributed to the draft manuscript preparation. All authors reviewed the results and approved the final version of the manuscript.

\section{Authors' information}

CC- Consultant Interventional Radiologist.

$\mathrm{GH}$ - Interventional Radiology Fellow.

\section{Funding}

The author(s) received no financial support for the research, authorship, and/ or publication of this article.

\section{Availability of data and materials}

The datasets used and subsequently analysed during the current study are available from the corresponding author on reasonable request.

\section{Declarations}

\section{Ethics approval and consent to participate}

Institutional review board approval was received for this retrospective study and the requirement for patient consent was waived.

\section{Competing interests}

The authors declare that they have no competing interests.

\section{Author details}

${ }^{1}$ St James Hospital, Dublin, Ireland. ²Department of Radiology, St Vincent's University Hospital, Dublin, Ireland. ${ }^{3}$ School of Medicine, University College Dublin, Dublin, Ireland. ${ }^{4}$ Department of Medical Physics and Clinical Engineering, St Vincent's University Hospital, Dublin, Ireland.

Received: 3 October 2021 Accepted: 6 January 2022

Published online: 16 February 2022

\section{References}

Balter S, Hopewell JW, Miller DL, Wagner LK, Zelefsky MJ (2010) Fluoroscopically guided interventional procedures: a review of radiation effects on patients' skin and hair. Radiology 254(2):326-341. https://doi.org/10.1148/radiol.2542 082312

Barral M, Gardavaud F, Lassalle L, Ammar MB, Najdawi M, Razakamanantsoa L, Renard-Penna R, Cussenot O, Cornelis FH (2021) Limiting radiation exposure during prostatic arteries embolization: influence of patient characteristics, anatomical conditions, and technical factors. Eur Radiol 31(9):6471-6479. https://doi.org/10.1007/s00330-021-07844-7

Baumann F, Peña C, Kloeckner R, Katzen BT, Gandhi R, Benenati JB (2017) The effect of a new angiographic imaging technology on radiation dose in visceral embolization procedures. Vasc Endovasc Surg 51(4):183-187. https:// doi.org/10.1177/1538574417698903

Beebe MJ, Jenkins P, Rothberg DL, Kubiak EN, Higgins TF (2016) Prospective assessment of the oncogenic risk to patients from fluoroscopy during trauma surgery. J Orthop Trauma 30(7):e223-e229. https://doi.org/10.1097/BOT. 0000000000000543

Bundy JJ, Chick JFB, Hage AN, Gemmete JJ, Srinivasa RN, Johnson EJ, Christodoulou E, Srinivasa RN (2018) Contemporary interventional radiology dosimetry: analysis of 4,784 discrete procedures at a single institution. J Am Coll Radiol 15(9):1214-1221. https://doi.org/10.1016/j.jacr.2018.06.004

Buytaert D, Eloot L, Mauti M, Drieghe B, Gheeraert P, Taeymans Y, Bacher K (2018) Evaluation of patient and staff exposure with state of the art X-ray technology in cardiac catheterization: a randomized controlled trial. J Interv Cardiol 31(6):807-814. https://doi.org/10.1111/joic.12553

Foley PT, Ganeshan A, Anthony S, Uberoi R (2010) Multi-detector CT angiography for lower gastrointestinal bleeding: can it select patients for endovascular intervention? J Med Imaging Radiat Oncol 54(1):9-16. https://doi.org/1 0.1111/j.1754-9485.2010.02131.x

Hansmann J, Henzler T, Gaba RC, Morelli JN (2017) Radiation dose reduction: comparative assessment of publication volume between interventional and diagnostic radiology. Diagn Interv Radiol 23(3):223-226. https://doi.org/10.51 52/dir.2016.16196

Hendee WR, O'Connor MK (2012) Radiation risks of medical imaging: separating fact from fantasy. Radiology 264(2):312-321. https://doi.org/10.1148/ra diol.12112678

Hur S, Jae HJ, Lee M, Kim HC, Chung JW (2014) Safety and efficacy of transcatheter arterial embolization for lower gastrointestinal bleeding: a single-center experience with 112 patients. J Vasc Interv Radiol 25(1):10-19. https://doi.org/10.1016/j.jvir.2013.09.012

International Atomic Energy Agency (IAEA) (2018) Radiation Protection and Safety in Medical Uses of Ionizing Radiation, IAEA Safety Standards Series No. SSG-46. IAEA, Vienna

Jacovides CL, Nadolski G, Allen SR, Martin ND, Holena DN, Reilly PM, Trerotola S, Braslow BM, Kaplan LJ, Pascual UL (2015) Arteriography for lower gastrointestinal hemorrhage: role of preceding abdominal computed tomographic angiogram in diagnosis and localization. JAMA Surg 150(7): 650-656. https://doi.org/10.1001/jamasurg.2015.97

Lacayo EA, Khera SS, Spies JB (2020) Impact of patient and procedure-related factors on radiation exposure from uterine artery embolization. Cardiovasc Intervent Radiol 43(1):120-126. https://doi.org/10.1007/s00270-019-02321-7

Lam DL, Larson DB, Eisenberg JD, Forman HP, Lee Cl (2015) Communicating potential radiation-induced Cancer risks from medical imaging directly to patients. AJR Am J Roentgenol 205(5):962-970. https://doi.org/10.2214/AJR.1 5.15057

Lin EC (2010) Radiation risk from medical imaging. Mayo Clin Proc 85(12):11421146. https://doi.org/10.4065/mcp.2010.0260

Loffroy R, Rao P, Ota S, de Lin M, Kwak BK, Geschwind JF (2010) Embolization of acute nonvariceal upper gastrointestinal hemorrhage resistant to endoscopic treatment: results and predictors of recurrent bleeding. Cardiovasc Intervent Radiol 33(6):1088-1100. https://doi.org/10.1007/s00270-010-9829-7

Meineke A, Rubbert C, Sawicki LM, Thomas C, Klosterkemper Y, Appel E, Caspers J, Bethge OT, Kröpil P, Antoch G, Boos J (2019) Potential of a machinelearning model for dose optimization in $\mathrm{CT}$ quality assurance. Eur Radiol 29(7):3705-3713. https://doi.org/10.1007/s00330-019-6013-6

Miller DL, Balter S, Cole PE, Lu HT, Schueler BA, Geisinger M, Berenstein A, Albert R, Georgia JD, Noonan PT, Cardella JF, St George J, Russell EJ, Malisch TW, Vogelzang RL, Miller GL 3rd, Anderson J, RAD-IR study (2003) Radiation doses in interventional radiology procedures: the RAD-IR study: part I: overall measures of dose. J Vasc Interv Radiol 14(6):711-727. https://doi.org/10.1097/ 01.RVI.0000079980.80153.4B

Miller DL, Kwon D, Bonavia GH (2009) Reference levels for patient radiation doses in interventional radiology: proposed initial values for U.S. practice. Radiology 253(3):753-764. https://doi.org/10.1148/radiol.2533090354

Mullady DK, Wang AY, Waschke KA (2020) AGA clinical practice update on endoscopic therapies for non-variceal upper gastrointestinal bleeding: expert review. Gastroenterology 159(3):1120-1128. https://doi.org/10.1053/j.gastro.2 020.05.095

Neri E et al (2019) What the radiologist should know about artificial intelligence an ESR white paper. Insights into Imaging 10(1):44. https://doi.org/10.1186/ s13244-019-0738-2

Schernthaner RE, Duran R, Chapiro J, Wang Z, Geschwind JFH, Lin MD (2015) A new angiographic imaging platform reduces radiation exposure for patients with liver cancer treated with transarterial chemoembolization. Eur Radiol 25(11):3255-3262. https://doi.org/10.1007/s00330-015-3717-0

Semelka RC, Armao DM, Elias J Jr, Picano E (2012) The information imperative: is it time for an informed consent process explaining the risks of medical radiation? Radiology 262(1):15-18. https://doi.org/10.1148/radiol.11110616

Shukla PA, Zybulewski A, Kolber MK, Berkowitz E, Silberzweig J, Hayim M (2017) No catheter angiography is needed in patients with an obscure acute gastrointestinal bleed and negative CTA. Clin Imaging 43:106-109. https:// doi.org/10.1016/j.clinimag.2017.02.006

Sommer $C$ et al (2010) Patients with life-threatening arterial renal hemorrhage: $C T$ angiography and catheter angiography with subsequent superselective 
embolization. Cardiovasc Intervent Radiol 33(3):498-508. https://doi.org/10.1 007/s00270-009-9787-0

Spink C, Avanesov M, Schmidt T, Grass M, Schoen G, Adam G, Koops A, Ittrich H, Bannas P (2017) Noise reduction angiographic imaging technology reduces radiation dose during bronchial artery embolization. Eur J Radiol 97:115-118. https://doi.org/10.1016/j.ejrad.2017.10.029

Takakuwa KM, Estepa AT, Shofer FS (2010) Knowledge and attitudes of emergency department patients regarding radiation risk of $\mathrm{CT}$ : effects of age, sex, race, education, insurance, body mass index, pain, and seriousness of illness. AJR Am J Roentgenol 195(5):1151-1158. https://doi.org/10.2214/AJR. 09.3847

Thomaere E, Dehairs M, Laenen A, Mehrsima A, Timmerman D, Cornelissen S, op de Beeck K, Bosmans H, Maleux G (2018) A new imaging technology to reduce the radiation dose during uterine fibroid embolization. Acta Radiol 59(12):1446-1450. https://doi.org/10.1177/0284185118760064

Tsapaki V (2020) Radiation dose optimization in diagnostic and interventional radiology: current issues and future perspectives. Phys Med 79:16-21. https:// doi.org/10.1016/j.jmp.2020.09.015

Wells ML, Hansel SL, Bruining DH, Fletcher JG, Froemming AT, Barlow JM, Fidler $J L$ (2018) CT for evaluation of acute gastrointestinal bleeding. Radiographics 38(4):1089-1107. https://doi.org/10.1148/rg.2018170138

Zener R, Johnson P, Wiseman D, Pandey S, Mujoomdar A (2018) Informed consent for radiation in interventional radiology procedures. Can Assoc Radiol J 69(1):30-37. https://doi.org/10.1016/j.carj.2017.07.002

\section{Publisher's Note}

Springer Nature remains neutral with regard to jurisdictional claims in published maps and institutional affiliations.

\section{Submit your manuscript to a SpringerOpen ${ }^{\circ}$ journal and benefit from:}

- Convenient online submission

- Rigorous peer review

- Open access: articles freely available online

High visibility within the field

- Retaining the copyright to your article

Submit your next manuscript at $\boldsymbol{\nabla}$ springeropen.com 